\title{
Mobile spine chordoma: results of 166 patients from the AOSpine Knowledge Forum Tumor database
}

\author{
*Ziya L. Gokaslan, MD, ${ }^{1}$ Patricia L. Zadnik, BA,, Daniel M. Sciubba, MD,' \\ Niccole Germscheid, MSc, ${ }^{2}$ C. Rory Goodwin, MD, PhD, ${ }^{1}$ Jean-Paul Wolinsky, MD, ${ }^{1}$ \\ Chetan Bettegowda, MD, PhD, ${ }^{1}$ Mari L. Groves, MD, ${ }^{1}$ Alessandro Luzzati, MD, ${ }^{3}$ \\ Laurence D. Rhines, MD, ${ }^{4}$ Charles G. Fisher, MD, MHSc, ${ }^{5}$ Peter Pal Varga, MD, ${ }^{6}$ \\ Mark B. Dekutoski, MD, ${ }^{7}$ Michelle J. Clarke, MD, ${ }^{8}$ Michael G. Fehlings, MD, PhD, ${ }^{9}$ \\ Nasir A. Quraishi, FRCS, ${ }^{10}$ Dean Chou, MD, ${ }^{11}$ Jeremy J. Reynolds, MBChB, ${ }^{12}$ \\ Richard P. Williams, MD, ${ }^{13}$ Norio Kawahara, MD, ${ }^{14}$ and Stefano Boriani, MD ${ }^{15}$
}

1Department of Neurosurgery, Johns Hopkins University School of Medicine, Baltimore, Maryland; 'Research Department, AOSpine International, Davos, Switzerland; ${ }^{3}$ Section for Oncological Orthopaedics and Reconstruction of the Spine, IRCCS Istituto Orthopedico Galeazzi, Milan, Italy; ' ${ }^{4}$ Department of Neurosurgery, MD Anderson Cancer Center, The University of Texas, Houston, Texas; ${ }^{5}$ Department of Orthopaedics, Division of Spine, University of British Columbia and Vancouver Coastal Health, Vancouver, British Columbia, Canada; ${ }^{6}$ National Center for Spinal Disorders and Buda Health Center, Budapest, Hungary; ${ }^{7}$ Department of Orthopaedic Surgery, The CORE Institute, Sun City West, Arizona; ${ }^{8}$ Department of Neurosurgery, Mayo Clinic, Rochester, Minnesota; ' Department of Surgery, Division of Neurosurgery and Spinal Program, University of Toronto and Toronto Western Hospital, Toronto, Ontario, Canada; ${ }^{10} \mathrm{C} e n t r e$ for Spinal Studies and Surgery, Queen's Medical Centre, Nottingham University Hospital NHS Trust, Nottingham, United Kingdom; "11Department of Neurological Surgery, University of California San Francisco, California; ${ }^{12}$ Spinal Division, Nuffield Orthopedic Centre, University of Oxford, United Kingdom; ${ }^{13}$ Department of Orthopaedics, Princess Alexandra Hospital, Brisbane, Australia; ${ }^{14}$ Department of Orthopedic Surgery, Kanazawa University, Kanazawa, Japan; and ${ }^{15}$ Department of Oncologic and Degenerative Spine Surgery, Rizzoli Orthopaedic Institute, Bologna, Italy

OBJECT A chordoma is an indolent primary spinal tumor that has devastating effects on the patient's life. These lesions are chemoresistant, resistant to conventional radiotherapy, and moderately sensitive to proton therapy; however, en bloc resection remains the preferred treatment for optimizing patient outcomes. While multiple small and largely retrospective studies have investigated the outcomes following en bloc resection of chordomas in the sacrum, there have been few large-scale studies on patients with chordomas of the mobile spine. The goal of this study was to review the outcomes of surgically treated patients with mobile spine chordomas at multiple international centers with respect to local recurrence and survival. This multiinstitutional retrospective study collected data between 1988 and 2012 about prognosispredicting factors, including various clinical characteristics and surgical techniques for mobile spine chordoma. Tumors were classified according to the Enneking principles and analyzed in 2 treatment cohorts: Enneking-appropriate (EA) and Enneking-inappropriate (EI) cohorts. Patients were categorized as EA when the final pathological assessment of the margin matched the Enneking recommendation; otherwise, they were categorized as El.

METHODS Descriptive statistics were used to summarize the data (Student t-test, chi-square, and Fisher exact tests). Recurrence and survival data were analyzed using Kaplan-Meier survival curves, log-rank tests, and multivariate Cox proportional hazard modeling.

RESULTS A total of 166 patients (55 female and 111 male patients) with mobile spine chordoma were included. The median patient follow-up was 2.6 years (range 1 day to 22.5 years). Fifty-eight (41\%) patients were EA and 84 (59\%) patients were El. The type of biopsy $(p<0.001)$, spinal location $(p=0.018)$, and if the patient received adjuvant therapy $(p<0.001)$ were significantly different between the 2 cohorts. Overall, $58(35 \%)$ patients developed local recurrence and 57 (34\%) patients died. Median survival was 7.0 years postoperative: 8.4 years postoperative for EA patients and 6.4 years postoperative for El patients $(p=0.023)$. The multivariate analysis showed that the El cohort was significantly

ABBREVIATIONS EA = Enneking appropriate; $\mathrm{EI}=$ Enneking inappropriate .

SUBMITTED February 18, 2015. ACCEPTED July 13, 2015.

INCLUDE WHEN CITING Published online December 18, 2015; DOI: 10.3171/2015.7.SPINE15201.

* Dr. Gokaslan and Ms. Zadnik contributed equally to this work. 


\begin{abstract}
associated with an increased risk of local recurrence in comparison with the EA cohort (HR 7.02; 95\% Cl 2.96-16.6; $p<$
\end{abstract} 0.001), although no significant difference in survival was observed.

CONCLUSIONS EA resection plays a major role in decreasing the risk for local recurrence in patients with chordoma of the mobile spine.

http://thejns.org/doi/abs/10.3171/2015.7.SPINE15201

KEY WORDS chordoma; mobile spine; Enneking classification; survival; recurrence; surgery; tumor; oncology

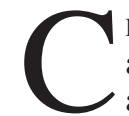
HORDOMAS are indolent primary spine tumors that arise from primitive notochordal rest cells. They are predominantly found in men and demonstrate a peak incidence at 40 to 60 years of age and an overall incidence of 0.8 per 100,000 people. ${ }^{12,14,15}$ Anatomically, chordomas are distributed throughout the spine, with the greatest incidence in the sacrococcygeal region $(45 \%-50 \%)$ followed by the spheno-occipital location $(35 \%-40 \%)$ and mobile spine $(10 \%-15 \%) .{ }^{12}$ Classically, chordomas have an indolent natural history and may grow to very large sizes, thereby making en bloc resection challenging. Current reviews cite an overall median survival of 6.29 years with 5-, 10-, and 20-year survival rates of $67.6 \%, 39.9 \%$, and $13.1 \%$, respectively. ${ }^{12}$ A number of studies have suggested that en bloc resection improves patient survival and decreases recurrence; however, the majority of published studies are small single-center reviews of patients with chordomas of the clivus or sacrum, as enrolling sufficient numbers of mobile spine chordoma patients is difficult. ${ }^{1,2,5,10,13-17,19,20}$ Unfortunately, data on the surgical management of mobile spine chordomas are limited, and this represents a critical knowledge gap. To date, the largest published study included 15 retrospective cases of primary mobile spine chordoma with 37 prospective cases. ${ }^{1}$

While en bloc resection is a surgical technique, Enneking-appropriate (EA) resection is a classification system that takes into account the grade of the tumor and the extent of tumor invasion into the surrounding tissues in order to determine the surgical margins to be achieved. Marginal or wide surgical margins would necessitate en bloc resection. The system was originally designed for musculoskeletal tumors of the appendicular skeleton; however, its principles have been extended to primary tumors of the spine. ${ }^{7,9}$ In a study on primary bone tumors of the spine, the authors demonstrated a significant reduction in local recurrence in patients with EA resection. ${ }^{9}$

The primary purpose of this study was to analyze a large cohort of patients with mobile spine chordomas who were treated at multiple international hospitals and determine if Enneking appropriateness influenced local recurrence and survival. The secondary goal was to identify other prognostic factors related to local recurrence and survival.

\section{Methods}

An international, multiinstitutional (13 institutions), retrospective review with cross-sectional follow-up was conducted. ${ }^{8}$ The patients included in the study had a diagnosis of chordoma, underwent surgical intervention between May 1988 and July 2012, and received regular surgical follow-up at one of the participating spine centers. Patients were excluded if they were admitted for the treatment of a metastatic spinal tumor or diagnosed with a primary spinal cord tumor. Each participating spine center received ethical approval for the study.

Demographic data, tumor histology, final pathological resection margins, Enneking stage, Weinstein-Boriani-Biagini stage, local recurrence, and survival data were collected from the clinical charts and institutional databases. Data were captured using a secure Web-based application (REDCap). Whenever necessary, government databases were accessed to retrieve data concerning survival.

Patients were analyzed in 2 different groups: EA and Enneking inappropriate (EI). EA was defined by the final pathological margins that matched the Enneking-recommended surgical margins. EI was defined by the final pathological margins that did not match the surgical margins as recommended by the Enneking classification. For example, if the final pathology was intralesional and marginal margins were recommended, then this was considered an EI procedure. Patients who underwent a previous resection of their chordoma that was described as intralesional were also considered EI.

\section{Surgical Technique}

A range of surgeon preferences and differences in tumor location, size, and aggressiveness lead to different surgical techniques being carried out. Some centers strictly follow Enneking principles, while others do not. Sometimes the proximity of critical anatomy and tumor extent prevent achieving the recommended margins.

\section{Pathological Results}

The final decision regarding the EA or EI margins was based on the pathological results of the surgical specimens, and the decision was made by an experienced musculoskeletal pathologist. Enneking classification distinguishes between wide and a marginal resection due to the complex anatomy of the spine. EA includes wide resection, marginal resection, and marginal margins (sparing of the dura is considered marginal resection).

\section{Adjuvant Therapy}

Exposure to adjuvant therapy, as defined as chemotherapy alone or intensity-modulated radiotherapy, external beam radiotherapy, or proton beam radiotherapy with or without chemotherapy, was documented for each patient. Chemotherapy regimens and radiation doses varied by institution. Across centers, the criteria for radiation referral 
included no current infection, history of radiation below the lifetime dose limits, and intralesional or en bloc marginal resection of the tumor. All reported adjuvant therapies were performed postoperatively before recurrence was noted.

\section{Statistical Analysis}

Descriptive statistics were used to summarize the data, namely the means and standard deviations for continuous variables and the absolute number and frequency distributions for categorical variables. Group differences were analyzed using the Student t-test for continuous variables or the chi-square tests (Pearson and Fisher exact tests, as appropriate) for categorical variables. Time to first local tumor recurrence and survival data, over a 10-year postoperative period, were analyzed using Kaplan-Meier survival curves and log-rank tests. Subsequently, multivariate Cox proportional hazards modeling was used to further investigate local recurrence and survival. Due to the issue of multicollinearity, some variables, although significant in the univariate analysis, were not included in the Cox regression model. Statistical significance was determined as $p \leq 0.05$. All statistical analyses were performed using STATA (version 12.0).

\section{Results}

\section{Patient Demographics and Tumor Characteristics}

Thirteen centers contributed data about 166 patients who were diagnosed with a primary mobile spine chordoma. Each center contributed an average of 12.8 patients to the cohort (range 2-48 patients). The patient demographics and clinical characteristics are summarized in Table 1. Patients had a mean age of $59 \pm 14$ years (range 18-84 years) at the time of surgery. Fifty-five (33\%) patients were female and $111(67 \%)$ patients were male. Fifty (30\%) patients had previously undergone spine chordoma resection, and 38 of $50(76 \%)$ patients were described as having intralesional resections and thus considered to have undergone EI procedures. The diagnosis of chordoma was predominantly made by CT-trocar biopsy $(\mathrm{n}=76 ; 60 \%)$. Among EA resected tumors, there was no difference in recurrence between different biopsy types $(\mathrm{p}=0.57)$. The median patient follow-up was 2.6 years (mean \pm SD 3.5 years \pm 2.6 years; range 1 day to 22.5 years).

Most of the mobile chordomas presented in the lumbar spine $(\mathrm{n}=78 ; 50 \%)$ and spanned only 1 vertebral level (n $=97 ; 58 \%$ ). The mean tumor size was $4.9 \mathrm{~cm}$ (range $1-21 \mathrm{~cm}$ ) from anterior to posterior, $4.1 \mathrm{~cm}$ (range 1-18 $\mathrm{cm}$ ) from left to right, and $4.3 \mathrm{~cm}$ (range $0.3-17 \mathrm{~cm}$ ) from cephalad to caudad. According to the Enneking classification, tumors were frequently classified as low grade (Grade I) $(n=94 ; 63 \%)$. The characteristics of the chordomas are presented in Table 2.

\section{Resection and Enneking Appropriateness}

Fifty-eight (41\%) patients were EA and 84 (59\%) patients were EI. In Table 3, the clinical characteristics of each cohort are summarized and compared. The type of biopsy performed $(\mathrm{p}<0.001)$, the spinal location of the tumor $(\mathrm{p}=0.018)$, and if the patient received adjuvant ther-
TABLE 1. Summary of patient demographic and clinical characteristics

\begin{tabular}{|c|c|}
\hline Variable & Value* \\
\hline Mean age at surgery $(y r s)(n=166)$ & $59 \pm 14$ \\
\hline$<55$ & $55(33)$ \\
\hline $55-64$ & $51(31)$ \\
\hline$\geq 65$ & $60(36)$ \\
\hline \multicolumn{2}{|l|}{$\operatorname{Sex}(n=166)$} \\
\hline Female & $55(33)$ \\
\hline Male & $111(67)$ \\
\hline \multicolumn{2}{|l|}{ Pain at diagnosis $(n=159)$} \\
\hline No & $17(11)$ \\
\hline Yes & $142(89)$ \\
\hline \multicolumn{2}{|c|}{ Pathological fracture at diagnosis $(n=160)$} \\
\hline No & $131(82)$ \\
\hline Yes & $29(18)$ \\
\hline \multicolumn{2}{|c|}{ Previous spine tumor operation $(n=165)$} \\
\hline No & $115(70)$ \\
\hline Yes & $50(30)$ \\
\hline \multicolumn{2}{|l|}{ Diagnostic method $(n=126)$} \\
\hline Open biopsy & $29(23)$ \\
\hline CT-trocar biopsy & $76(60)$ \\
\hline Intraoperative biopsy & $21(17)$ \\
\hline \multicolumn{2}{|l|}{ Enneking appropriateness $(n=142)$} \\
\hline EA & $58(41)$ \\
\hline El & $84(59)$ \\
\hline \multicolumn{2}{|l|}{ Adjuvant therapy $(n=166)$} \\
\hline No & $81(49)$ \\
\hline Yes & $85(51)$ \\
\hline \multicolumn{2}{|l|}{ Local recurrence $(n=166)$} \\
\hline No & $108(65)$ \\
\hline Yes & $58(35)$ \\
\hline \multicolumn{2}{|l|}{ Survival $(n=166)$} \\
\hline Alive & $109(66)$ \\
\hline Dead & $57(34)$ \\
\hline
\end{tabular}

apy $(\mathrm{p}<0.001)$ were significantly different between the 2 groups. Factors such as age, sex, tumor grade, and tumor volume were not found to differ significantly, while evidence regarding the number of vertebral levels spanned by the tumor trended toward significance $(p=0.057)$.

\section{Local Recurrence}

Fifty-eight $(35 \%)$ patients experienced local tumor recurrence following resection, and 108 (65\%) patients had no documented local tumor recurrence following surgery. Median time to first local recurrence after surgery was 5.3 years (95\% CI $4.2-6.7$ years). Nine (16\%) EA patients presented with a local recurrence in comparison with 39 (46\%) EI patients. The results of the univariate associations between the development of local recurrence and the 
TABLE 2. Summary of the chordoma characteristics

\begin{tabular}{lc}
\hline \multicolumn{1}{c}{ Variable } & Value* \\
\hline Spinal location $(\mathrm{n}=156)$ & \\
\hline Cervical & $54(35)$ \\
\hline Thoracic & $24(15)$ \\
\hline Lumbar & $78(50)$ \\
\hline No. of vertebral levels spanned by tumor $(\mathrm{n}=166)$ & $97(58)$ \\
\hline 1 & $69(42)$ \\
\hline$\geq 2$ & \\
\hline Tumor grade $(\mathrm{n}=150)$ & $94(63)$ \\
\hline Low (Grade I) & $56(37)$ \\
\hline High (Grade II) & $4.9 \pm 3.1$ \\
\hline Tumor size $(\mathrm{cm})$ & $4.1 \pm 2.4$ \\
\hline Anterior-posterior $(\mathrm{n}=122)$ & $4.3 \pm 2.5$ \\
\hline Left-right $(\mathrm{n}=122)$ & $87.7 \pm 317.6$ \\
\hline Cephalad-caudad $(\mathrm{n}=119)$ & $42(35)$ \\
\hline Tumor vol ellipsoid body $\left(\mathrm{cm}^{3}\right)(\mathrm{n}=119) \dagger$ & $40(34)$ \\
\hline$<20$ & $37(31)$ \\
\hline $20-59$ &
\end{tabular}

* Data are presented as number of patients (\%) unless specified otherwise.

Mean values are presented as mean $\pm \mathrm{SD}$.

$\dagger$ Tumor volume ellipsoid body $=\pi / 6 \times$ height $\times$ width $\times$ depth

study characteristics over the 10-year postoperative period are shown in Table 4. Time-to-event data were unknown for 4 patients; therefore, 162 of 166 patients were evaluated. Patients who underwent an EI resection had a median time to first local recurrence of 2.4 years $(95 \% \mathrm{CI}$ 1.8-4.2 years), while for EA patients the median time to recurrence was not reached during the analysis period ( $\mathrm{p}$ $<0.001$ ) (Fig. 1). Intralesional excision significantly increased the risk for local recurrence $(\mathrm{p}<0.001)$. Patients who received adjuvant therapy were more likely to develop local recurrence postoperatively $(\mathrm{p}=0.006)$. There was no significant relationship between local recurrence and patient age at surgery, type of biopsy performed, spinal location of the tumor, number of vertebral levels spanned by the tumor, tumor grade, and tumor volume in the univariate analysis.

In the multivariate analysis, an EI procedure was significantly associated with a high risk of local recurrence in comparison with an EA procedure (HR 7.02; 95\% CI 2.96-16.6; $p<0.001$ ) (Table 5). Age at the time of surgery and adjuvant therapy did not significantly increase the HR for local recurrence.

\section{Survival}

Fifty-seven (34\%) patients had died at the time of last follow-up. Median survival after surgery for all patients was 7.0 years (95\% CI 5.3-8.4 years). Thirteen (22\%) EA patients died in comparison with $32(38 \%)$ EI patients. The results of the univariate associations between the survival and study characteristics over the 10-year postoperative period are shown in Table 4. Median survival after surgery for EA patients was 8.4 years $(95 \%$ CI 6.9 years to
TABLE 3. Study characteristics according to Enneking appropriateness

\begin{tabular}{|c|c|c|c|}
\hline \multirow[b]{2}{*}{ Variable } & \multicolumn{2}{|c|}{ Value $^{*}$} & \multirow[b]{2}{*}{$\mathrm{p}$ Value } \\
\hline & EA & El & \\
\hline Age at surgery (yrs) $(n=142)$ & $57.1 \pm 13.8$ & $61.5 \pm 13.7$ & $0.063 \S$ \\
\hline \multicolumn{4}{|l|}{$\operatorname{Sex}(n=142)$} \\
\hline Female & $19(33)$ & $30(36)$ & \multirow[t]{2}{*}{$0.716 \ddagger$} \\
\hline Male & $39(67)$ & $54(64)$ & \\
\hline \multicolumn{4}{|l|}{ Diagnostic method $(n=110)$} \\
\hline Open biopsy & $5(10)$ & $23(37)$ & \multirow[t]{3}{*}{$<0.001 \dagger$} \\
\hline CT-trocar biopsy & $39(81)$ & $23(37)$ & \\
\hline Intraoperative biopsy & $4(8)$ & $16(26)$ & \\
\hline \multicolumn{4}{|l|}{ Spinal location $(n=133)$} \\
\hline Cervical & $11(20)$ & $30(38)$ & \multirow[t]{3}{*}{$0.018 \ddagger$} \\
\hline Thoracic & $7(13)$ & $16(20)$ & \\
\hline Lumbar & $36(67)$ & $33(42)$ & \\
\hline \multicolumn{4}{|l|}{$\begin{array}{l}\text { No. of vertebral levels spanned } \\
\text { by tumor }(n=142)\end{array}$} \\
\hline 1 & $39(67)$ & $43(51)$ & \multirow[t]{2}{*}{$0.057 \ddagger$} \\
\hline$\geq 2$ & $19(33)$ & $41(49)$ & \\
\hline \multicolumn{4}{|l|}{ Tumor grade $(n=141)$} \\
\hline Low (Grade I) & $34(60)$ & $55(65)$ & \multirow[t]{2}{*}{$0.482 \ddagger$} \\
\hline High (Grade II) & $23(40)$ & $29(35)$ & \\
\hline \multicolumn{4}{|l|}{$\begin{array}{l}\text { Tumor vol ellipsoid body }\left(\mathrm{cm}^{3}\right) \\
\qquad(\mathrm{n}=113) \boldsymbol{\eta}\end{array}$} \\
\hline$<20$ & $14(27)$ & $24(39)$ & \multirow[t]{3}{*}{$0.169 \ddagger$} \\
\hline $20-59$ & $22(42)$ & $16(26)$ & \\
\hline$\geq 60$ & $16(31)$ & $21(34)$ & \\
\hline \multicolumn{4}{|l|}{ Adjuvant therapy $(n=138)$} \\
\hline No & $44(79)$ & $33(40)$ & \multirow[t]{2}{*}{$<0.001 \ddagger$} \\
\hline Yes & $12(21)$ & $49(60)$ & \\
\hline \multicolumn{4}{|l|}{ Local recurrence $(n=142)$} \\
\hline No & $49(84)$ & $45(54)$ & \multirow[t]{2}{*}{$<0.001 \ddagger$} \\
\hline Yes & $9(16)$ & $39(46)$ & \\
\hline \multicolumn{4}{|l|}{ Survival $(n=142)$} \\
\hline Alive & $45(78)$ & $52(62)$ & \multirow[t]{2}{*}{$0.048 \ddagger$} \\
\hline Dead & $13(22)$ & $32(38)$ & \\
\hline \multicolumn{4}{|c|}{$\begin{array}{l}\text { * Data are presented as number of patients }(\%) \text { unless noted otherwise. Mean } \\
\text { values are presented as the } \pm \mathrm{SD} \text {. } \\
\dagger \text { Fisher exact test. } \\
\text { † Chi-square test. } \\
\text { § Student t-test. } \\
\text { ๆ Tumor volume ellipsoid body }=\pi / 6 \times \text { height } \times \text { width } \times \text { depth. }\end{array}$} \\
\hline
\end{tabular}

undefined) versus 6.4 years (95\% CI 4.8-8.5 years) for EI patients $(\mathrm{p}=0.023)$ (Fig. 2). Adjuvant therapy was associated with a significant decrease in patient survival $(\mathrm{p}=$ 0.024). Tumors that spanned more than 1 vertebral level were also associated with a significant decrease in survival $(p=0.027)$. There was no evidence for a significant relationship between survival and patient age at surgery, type of biopsy performed, spinal location of the tumor, tumor grade, tumor volume, and pathological results. There was some borderline evidence that the intralesional exci- 
TABLE 4. Univariate results derived from the log-rank test used to evaluate the development of local recurrence and survival over a 10-year period following resection

\begin{tabular}{|c|c|c|c|c|c|c|}
\hline \multirow[b]{2}{*}{ Variable } & \multicolumn{3}{|c|}{ Local Recurrence* } & \multicolumn{3}{|c|}{ Survival } \\
\hline & $\begin{array}{l}\text { No. of } \\
\text { Patients }\end{array}$ & $\begin{array}{l}\text { No. of Observed Events } \\
\text { (recurrences) }\end{array}$ & $p$ Value & $\begin{array}{l}\text { No. of } \\
\text { Patients }\end{array}$ & $\begin{array}{l}\text { No. of Observed } \\
\text { Events (deaths) }\end{array}$ & $\mathrm{p}$ Value \\
\hline \multicolumn{7}{|l|}{ Age at surgery (yrs) } \\
\hline$<55$ & 50 & 14 & \multirow[t]{3}{*}{0.201} & 52 & 15 & \multirow[t]{3}{*}{0.335} \\
\hline $55-64$ & 54 & 21 & & 56 & 19 & \\
\hline$\geq 65$ & 58 & 19 & & 58 & 22 & \\
\hline \multicolumn{7}{|l|}{ Diagnostic method } \\
\hline Open biopsy & 29 & 7 & \multirow[t]{3}{*}{0.197} & 29 & 9 & \multirow[t]{3}{*}{0.439} \\
\hline CT-trocar biopsy & 76 & 24 & & 76 & 27 & \\
\hline Intraoperative biopsy & 19 & 8 & & 21 & 11 & \\
\hline \multicolumn{7}{|l|}{ Spinal location } \\
\hline Cervical & 53 & 16 & \multirow[t]{3}{*}{0.138} & 54 & 20 & \multirow[t]{3}{*}{0.137} \\
\hline Thoracic & 24 & 9 & & 24 & 9 & \\
\hline Lumbar & 75 & 26 & & 78 & 26 & \\
\hline \multicolumn{7}{|c|}{ No. of vertebral levels spanned by the tumor } \\
\hline 1 & 96 & 37 & \multirow[t]{2}{*}{0.541} & 97 & 32 & \multirow[t]{2}{*}{0.027} \\
\hline$\geq 2$ & 66 & 17 & & 69 & 24 & \\
\hline \multicolumn{7}{|l|}{ Tumor grade } \\
\hline Low (Grade I) & 93 & 33 & \multirow[t]{2}{*}{0.245} & 94 & 27 & \multirow[t]{2}{*}{0.622} \\
\hline High (Grade II) & 53 & 16 & & 56 & 23 & \\
\hline \multicolumn{7}{|c|}{ Tumor vol ellipsoid body $\left(\mathrm{cm}^{3}\right) \dagger$} \\
\hline$<20$ & 41 & 14 & \multirow[t]{3}{*}{0.589} & 42 & 14 & \multirow[t]{3}{*}{0.579} \\
\hline $20-59$ & 39 & 12 & & 40 & 16 & \\
\hline$\geq 60$ & 37 & 7 & & 37 & 7 & \\
\hline \multicolumn{7}{|c|}{ Pathological results of the surgical specimen } \\
\hline Intralesional & 67 & 34 & \multirow[t]{2}{*}{$<0.001$} & 68 & 26 & \multirow[t]{2}{*}{0.060} \\
\hline Marginal or wide & 71 & 11 & & 72 & 17 & \\
\hline \multicolumn{7}{|l|}{ Enneking appropriateness } \\
\hline EA & 57 & 8 & \multirow[t]{2}{*}{$<0.001$} & 58 & 13 & \multirow[t]{2}{*}{0.023} \\
\hline El & 83 & 38 & & 84 & 32 & \\
\hline \multicolumn{7}{|l|}{ Adjuvant therapy } \\
\hline No & 81 & 22 & \multirow[t]{2}{*}{0.006} & 81 & 22 & 0.024 \\
\hline Yes & 77 & 29 & & 81 & 31 & \\
\hline
\end{tabular}

* Complete information is available for 162 of 166 patients.

$\dagger$ Tumor volume ellipsoid body $=\pi / 6 \times$ height $\times$ width $\times$ depth.

sion margin was associated with a decrease in survival ( $\mathrm{p}$ $=0.060$ ).

In the multivariate analysis, the significant findings of the univariate analysis were attenuated. Age at the time of surgery, Enneking appropriateness, number of vertebral levels spanned by the tumor, and the use of adjuvant therapy did not significantly impact survival (Table 5).

\section{Discussion}

The Enneking classification provides the surgeon with a measure of when to aggressively resect with marginal or wide margins and when the patient is unlikely to benefit from an aggressive en bloc procedure. The score has been extensively evaluated and found to have near-perfect intraobserver reliability; however, the recommended margins can be difficult to achieve in the spine when secondary to complex and critical surgical anatomy. ${ }^{3}$ In the present study, EI patients were statistically more likely to have a recurrence $(p<0.001)$ based on the univariate analysis and demonstrated a significantly shorter median survival (6.4 years) in comparison with EA patients $(8.4$ years; $p=$ $0.023)$. The type of biopsy $(\mathrm{p}<0.001)$, spinal location ( $\mathrm{p}$ $=0.018)$, and if the patient received adjuvant therapy ( $\mathrm{p}<$ 0.001 ) were significantly different between the 2 cohorts. On the multivariate analysis, however, these differences in survival were not statistically significant. These data suggest that surgeons should use the Enneking scoring system to guide their surgical decision-making; however, the 


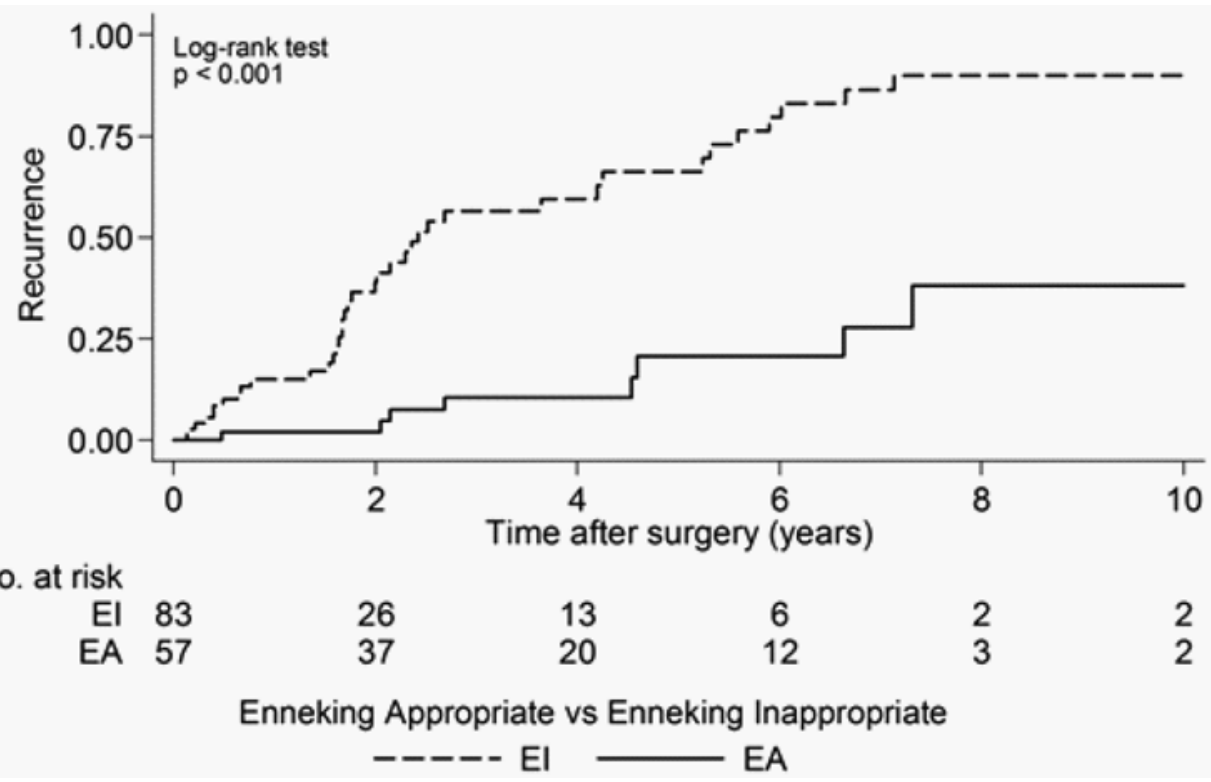

FIG. 1. Kaplan-Meier analysis of time to first local recurrence following surgery. The number at risk indicates the number of EA and El patients patients included in the analysis. Patients with El resection had a median time to local recurrence of 2.4 years, while the median time to first local recurrence for the EA patients was not reached in this analysis.

TABLE 5. Results of the multivariate Cox regression analysis of local recurrence and survival over a 10 -year period following resection

\begin{tabular}{|c|c|c|}
\hline \multirow[b]{2}{*}{ Variable } & \multicolumn{2}{|c|}{ Local Recurrence } \\
\hline & $\mathrm{HR}(95 \% \mathrm{Cl})$ & $\mathrm{p}$ Value \\
\hline \multicolumn{3}{|l|}{ Local recurrence } \\
\hline \multicolumn{3}{|l|}{ Age at surgery } \\
\hline Age/1 yr* & $1.01(0.99-1.04)$ & 0.375 \\
\hline \multicolumn{3}{|c|}{ Enneking appropriateness } \\
\hline EA & Reference & \multirow[t]{2}{*}{$<0.001$} \\
\hline El & $7.02(2.96-16.6)$ & \\
\hline \multicolumn{3}{|l|}{ Adjuvant therapy } \\
\hline No & Reference & \multirow[t]{2}{*}{0.848} \\
\hline Yes & $0.94(0.50-1.77)$ & \\
\hline \multicolumn{3}{|l|}{ Survival } \\
\hline \multicolumn{3}{|l|}{ Age at surgery } \\
\hline Age/1 yr* & $1.02(0.99-1.04)$ & 0.157 \\
\hline \multicolumn{3}{|c|}{ Enneking appropriateness } \\
\hline EA & Reference & \multirow[t]{2}{*}{0.249} \\
\hline El & $1.55(0.74-3.27)$ & \\
\hline \multicolumn{3}{|c|}{$\begin{array}{l}\text { No. of vertebral levels spanned } \\
\text { by the tumor }\end{array}$} \\
\hline 1 & Reference & \multirow[t]{2}{*}{0.065} \\
\hline$\geq 2$ & $1.86(0.96-3.58)$ & \\
\hline \multicolumn{3}{|l|}{ Adjuvant therapy } \\
\hline No & Reference & \multirow[t]{2}{*}{0.228} \\
\hline Yes & $1.52(0.77-2.99)$ & \\
\hline
\end{tabular}

* Age per 1-year increment. population of patients with chordomas is heterogeneous, and multiple factors may complicate the direct application of this scoring system. For example, EI patients may have undergone incomplete or intralesional resection due to complex anatomical limitations, such as intravascular invasion or threat to a vital structure, rather than the surgeon's unwillingness to aggressively resect the lesion. For these reasons, an analysis of EI versus EA resections should be considered carefully.

The results of this study further support the importance of marginal or wide resection when possible in order to decrease recurrence. In this study, marginal or wide resection was significantly associated with a lower risk of local recurrence compared with patients who underwent intralesional resection ( $\mathrm{p}<0.001)$. Furthermore, intralesional excision significantly increased the risk for local recurrence ( $\mathrm{p}<0.001)$. Patients who received adjuvant therapy were more likely to develop local recurrence postoperatively ( $\mathrm{p}$ $=0.006$ ) and demonstrate a significant decrease in survival $(p=0.024)$. The significance of adjuvant therapy, with respect to local recurrence and survival, likely reflects selection bias based on treatment paradigms for patients with gross contamination during resection. The utility of either neoadjuvant or postoperative adjuvant radiotherapy (e.g., proton/photon beam, stereotactic) was not rigorously assessed in our study, however several studies have demonstrated high local control rates after radiotherapy. ${ }^{6,11,18,21}$ For instance, high-dose single fraction stereotactic radiosurgery and primary adjuvant photon/proton therapy after surgery have demonstrated good tumor control with low treatment-related morbidity. $6,11,18,21$ These studies also demonstrate better local control rates in primary chordoma relative to recurrent tumors at 2-year follow-up, although studies with long-term data are still needed to determine 


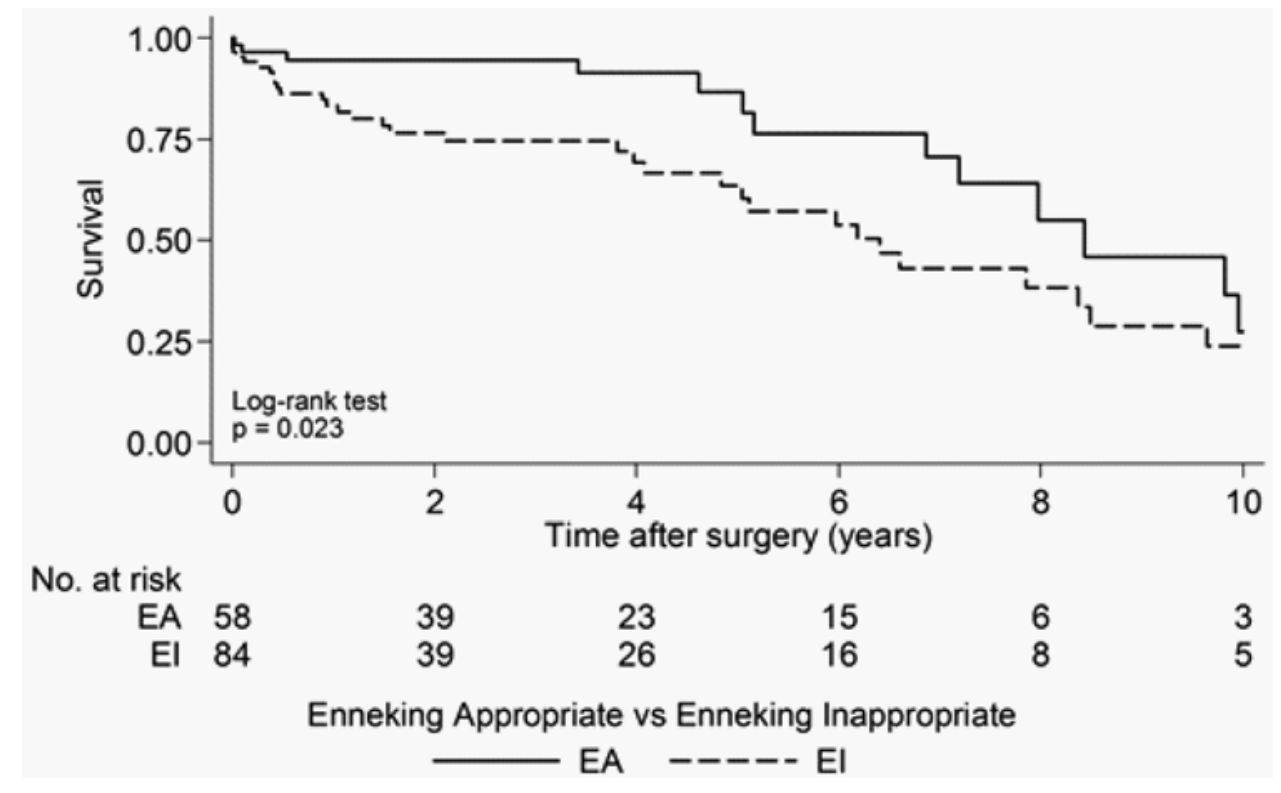

FIG. 2. Kaplan-Meier analysis of survival following surgery. The number at risk indicates the number of EA and El patients included in the analysis. Median survival was reached at 8.4 years postoperatively for EA patients and 6.4 years postoperatively for El patients.

the efficacy of radiotherapy on local disease control. Although patient survival was unchanged in the wide or marginal versus intralesional resection groups, other variables outside the scope of this study may reflect how recurrence impacts the patient's life. In future studies, prospective data collection will be essential to understanding how decreased recurrence impacts patient quality of life, the use of adjuvant therapy, and functional status.

Of note, patients with chordoma often undergo multiple surgical procedures. Choi et al. reported a series of 97 patients who underwent a total of 132 operations. ${ }^{4}$ Their overall survival rates at 5 and 10 years were $55 \%$ and $36 \%$, respectively. They found that patients who underwent prior resections at different institutions demonstrated worse survival than patients who had their primary surgery at the authors' centers. They concluded that attempting the most radical primary resection was warranted, as patients with recurrence have a much lower rate of successful resection. ${ }^{4}$

We acknowledge that the present study has several key limitations. First, the patients included in this study were accrued via a retrospective database, and, as such, the data are incomplete. Furthermore, while the inclusion of patients from multiple centers improves the generalizability of the data and conclusions, variations in data recording, treatment paradigms (e.g., surgical technique, adjuvant therapy), and classification by pathologists and radiologists may have contributed to a lack of uniformity across the patient sample. Also, another limitation is that our recurrence data are based on a median patient follow-up period of 2.6 years, whereas the median time to first local recurrence after surgery was 5.3 years. Other limitations include the types of biopsy performed and the adjuvant therapy regimens. In contrast, the strength of the current study was the inclusion of a large sample size with patient data from multiple countries and hospitals. Furthermore, we carefully constructed the study instrument and met regularly to discuss data collection and standardization of the data reporting and analysis.

\section{Conclusions}

We report the largest cohort of patients with chordoma of the mobile spine, with 166 patients from 13 international medical centers. The data from this study are consistent with the findings from the mobile spine chordoma literature and support performing EA surgical procedures on all patients due to the significant reduction in the risk of tumor recurrence.

\section{Acknowledgments}

We are grateful to the collaborating centers' local clinical research personnel and support staff for their active participation. This study was organized and funded by AOSpine International through the AOSpine Knowledge Forum Tumor, a pathologyfocused working group of up to 10 international spine experts acting on behalf of AOSpine in their domains of scientific expertise. Study support was provided directly through AOSpine's research department and the AO Foundation's clinical investigation documentation unit.

\section{References}

1. Boriani S, Bandiera S, Biagini R, Bacchini P, Boriani L, Cappuccio M, et al: Chordoma of the mobile spine: fifty years of experience. Spine (Phila Pa 1976) 31:493-503, 2006

2. Boriani S, Biagini R, De Iure F, Bertoni F, Malaguti MC, Di Fiore M, et al: En bloc resections of bone tumors of the thoracolumbar spine. A preliminary report on 29 patients. Spine (Phila Pa 1976) 21:1927-1931, 1996 
3. Chan P, Boriani S, Fourney DR, Biagini R, Dekutoski MB, Fehlings MG, et al: An assessment of the reliability of the Enneking and Weinstein-Boriani-Biagini classifications for staging of primary spinal tumors by the Spine Oncology Study Group. Spine (Phila Pa 1976) 34:384-391, 2009

4. Choi D, Melcher R, Harms J, Crockard A: Outcome of 132 operations in 97 patients with chordomas of the craniocervical junction and upper cervical spine. Neurosurgery 66:5965,2010

5. Cloyd JM, Chou D, Deviren V, Ames CP: En bloc resection of primary tumors of the cervical spine: report of two cases and systematic review of the literature. Spine J 9:928-935, 2009

6. DeLaney TF, Liebsch NJ, Pedlow FX, Adams J, Weyman EA, Yeap BY, et al: Long-term results of Phase II study of high dose photon/proton radiotherapy in the management of spine chordomas, chondrosarcomas, and other sarcomas. J Surg Oncol 110:115-122, 2014

7. Enneking WF, Dunham WK: Resection and reconstruction for primary neoplasms involving the innominate bone. J Bone Joint Surg Am 60:731-746, 1978

8. Fisher CG, Goldschlager T, Boriani S, Varga PP, Rhines LD, Fehlings MG, et al: An evidence-based medicine model for rare and often neglected neoplastic conditions. J Neurosurg Spine 21:704-710, 2014

9. Fisher CG, Saravanja DD, Dvorak MF, Rampersaud YR, Clarkson PW, Hurlbert J, et al: Surgical management of primary bone tumors of the spine: validation of an approach to enhance cure and reduce local recurrence. Spine (Phila Pa 1976) 36:830-836, 2011

10. Fuchs B, Dickey ID, Yaszemski MJ, Inwards CY, Sim FH: Operative management of sacral chordoma. J Bone Joint Surg Am 87:2211-2216, 2005

11. Holliday EB, Mitra HS, Somerson JS, Rhines LD, Mahajan A, Brown PD, et al: Postoperative proton therapy for chordomas and chondrosarcomas of the spine: adjuvant versus salvage radiation therapy. Spine (Phila Pa 1976) 40:544-549, 2015

12. McMaster ML, Goldstein AM, Bromley CM, Ishibe N, Parry DM: Chordoma: incidence and survival patterns in the United States, 1973-1995. Cancer Causes Control 12:1-11, 2001

13. Meng T, Yin H, Li B, Li Z, Xu W, Zhou W, et al: Clinical features and prognostic factors of patients with chordoma in the spine: a retrospective analysis of 153 patients in a single center. Neuro Oncol 17:725-732, 2015

14. Mukherjee D, Chaichana KL, Adogwa O, Gokaslan Z, Aaronson O, Cheng JS, et al: Association of extent of local tumor invasion and survival in patients with malignant primary osseous spinal neoplasms from the Surveillance, Epidemiology, and End Results (SEER) database. World Neurosurg 76:580-585, 2011

15. Mukherjee D, Chaichana KL, Gokaslan ZL, Aaronson O, Cheng JS, McGirt MJ: Survival of patients with malignant primary osseous spinal neoplasms: results from the Surveillance, Epidemiology, and End Results (SEER) database from 1973 to 2003. J Neurosurg Spine 14:143-150, 2011
16. Noël G, Habrand JL, Mammar H, Pontvert D, Haie-Méder C, Hasboun D, et al: Combination of photon and proton radiation therapy for chordomas and chondrosarcomas of the skull base: the Centre de Protonthérapie D’Orsay experience. Int J Radiat Oncol Biol Phys 51:392-398, 2001

17. Ozaki T, Hillmann A, Winkelmann W: Surgical treatment of sacrococcygeal chordoma. J Surg Oncol 64:274-279, 1997

18. Park L, Delaney TF, Liebsch NJ, Hornicek FJ, Goldberg S, Mankin H, et al: Sacral chordomas: Impact of high-dose proton/photon-beam radiation therapy combined with or without surgery for primary versus recurrent tumor. Int J Radiat Oncol Biol Phys 65:1514-1521, 2006

19. Ruggieri P, Angelini A, Ussia G, Montalti M, Mercuri M: Surgical margins and local control in resection of sacral chordomas. Clin Orthop Relat Res 468:2939-2947, 2010

20. Thieblemont C, Biron P, Rocher F, Bouhour D, Bobin JY, Gérard JP, et al: Prognostic factors in chordoma: role of postoperative radiotherapy. Eur J Cancer 31A:2255-2259, 1995

21. Yamada Y, Laufer I, Cox BW, Lovelock DM, Maki RG, Zatcky JM, et al: Preliminary results of high-dose singlefraction radiotherapy for the management of chordomas of the spine and sacrum. Neurosurgery 73:673-680, 2013

\section{Disclosures}

Dr. Rhines is a consultant for Stryker and Globus. Dr. Sciubba is a consultant for Medtronic and Depuy-Synthes. Dr. Fisher is a consultant for Medtronic and Nuvasive and receives non-studyrelated clinical or research support from OREF. Dr. Chou is a consultant for Globus, Medtronic, and Orthofix. Ms. Germscheid has a nonfinancial relationship with AOSpine International. Dr. Goodwin is a UNCF-Merck Science Initiative Postdoctoral Fellow and has received an award from the Burroughs Wellcome Fund. Dr. Dekutoski holds patents with the Mayo Office of International Property and receives clinical or research support from the AO Foundation.

\section{Author Contributions}

Conception and design: Sciubba, Gokaslan, Germscheid, Fisher, Boriani. Acquisition of data: all authors. Analysis and interpretation of data: all authors. Drafting the article: Sciubba, Gokaslan, Zadnik, Germscheid. Critically revising the article: all authors. Reviewed submitted version of manuscript: all authors. Statistical analysis: Sciubba, Zadnik, Germscheid, Goodwin. Administrative/technical/material support: Sciubba, Zadnik, Germscheid. Study supervision: Sciubba, Gokaslan, Boriani.

\section{Correspondence}

Daniel M. Sciubba, Department of Neurosurgery, Johns Hopkins University School of Medicine, 600 N. Wolfe St., Meyer 5-185, Baltimore, MD 21287. email: dsciubb1@jhmi.edu. 